\title{
Teaching biathletes the rules of shooting using electronic devices
}

\author{
Nikolay Astafev ${ }^{1 *}$, Galina Kukleva ${ }^{2}$ \\ ${ }^{1}$ Tyumen Advanced Training Institute of the Russian Federation Ministry of Internal Affairs, 625049, \\ Tyumen, Russia \\ ${ }^{2}$ Physical Culture Institute of Tyumen State University, 625023, Tyumen, Russia
}

\begin{abstract}
An advanced direction in marksmanship training of biathletes is teaching the rules of shooting: "marking» of a shot; defining the mean point of impact; correcting the sight; offset shooting. Teaching the rules of shooting using electronic devices will help to achieve the aim without a coach and will help to save cartridges. The article presents the description of the teaching programs algorythms for electronic devices.
\end{abstract}

\section{Introduction}

Introduction was written with the decree of the Russia Ministry of Sport, November, 11, 2019 № 927 Federal experimental (innovative) platforms were adopted, including innovative project «Developing the system of training sports reserve in cross country skiing and biathlon by means of organizational, methodical, technological innovations on the basis of interregional resource-methodical center model (2019-2024)». State autonomous establishment of Tyumen region Federal experimental (innovative) platform was adopted «L.N. Noskova regional sports school of the Olympic reserve in cross country skiing and biathlon», regional social organization «Olympic Council of Tyumen region», Institute of physical culture of the Tyumen State University. The research is carried out in terms of the federal experimental (innovative) platform.

The research works show that biathletes-beginners should be taught the rules of shooting: «marking» of shooting; defining the mean point of impact; correcting the sight; offset shooting [1, 2, 3].

As the means of teching rules of shooting, for cartridges and coach's time saving, it is reasonable to use electronic devices $[4,5]$. All over the world there is the tendency of increasing the number of carried electronic devices. Users become more interested in wearable electronic devices Wearable Technologies (WT) than in laptops, pads and smartphones [6]. That is why the created teaching programs should be universal, should work at a computer, pad or smartphone.

In order to get a feedback, estimate the effectiveness of the teaching programs, improve the programs, specify estimating indices it is necessary to provide the access of young biathletes' wearable electronic devices to teaching programs through login and password from the sites of further education establishments in physical culture sphere.

\footnotetext{
* Corresponding author: astnic@ mail.ru
} 


\section{Materials and Methods}

The object of the research was the demands claimed on the programs for wearable electronic devices for teaching biathletes rules of shooting.

As the materials of the research we used the results of teaching biathletes and law enforcement officials rules of shooting with the help of earlier prepared by us computer programs. For biathletes - "marking" of a shot using dioptrical sight and ring sight, for law enforcement officials - "marking" a shot during shooting using open sight; defining the mean point of impact; offset shooting.

As the research methods we used scientific works analysis, summarizing methods, including a long-term experience of the author as biathlon coach-teacher, fire preparation teacher at educational establishments of Russia Ministry of Internal Affairs. During the research we used complex approach.

\section{Results and Discussion}

The base for creating the algorithms of teaching programs for electronic wearable devices was a long-term positive experience of using earlier created computer programs (with the direct participation of the author) in fire preparation of biathletes and law enforcement officials. They are used for teaching the rules of shooting («marking» of a shot; defining the mean point of impact; offset shooting.).

\subsection{Teaching "marking" of a shot}

In sports training of biathletes shooting training simulators SCATT were widely used. Training simulator SCATT hlps to follow the aiming point movement from the moment of gun induction till the shot; it marks the shot with the point at a target; reflects the aiming point movement after the shot $[7,8,9]$. We created the suggestions concerning software programs improvement at shooting training simulator SCATT [10]. At the same time, training simulator SCATT doesn't let control the position of aiming devices during the shot, "if a shooter saw mutual position of the aiming devices and the aim or not during the shot, if he saw them which one". Shooter's constant, same mistakes are possible during the aiming. For example, aiming with similar "uneven" front sight cover. That is why earlier we created and successfully tested the methodology of teaching biathletes "marking" a shot with the help of computer $[11,12]$. During creating the methodology of teaching "marking" a shot with the help of electronic wearable devices we took into consideration the experience of the program use. It was created for a computer.

Choosing (adjustment) aiming devices sizes: choosing the diameter of the hole of dioptrical sight; hole diameter of ring sight (rough (small)) - the average-free (big)); the kind of ring sight (the sight is attached to the front sight cover below or it is attached to the front sight cover on the left or on the right).

The objective for a student - when a student hears a shot he should remember mutual location of aimed equipment (make a shot "mark") and define the direction of a hole deviation from the center of the target (according to clock face rule).

The difficulty of tasks defining: time of aiming (can be defined 2, 3, 4, 5 seconds); discreteness of foresight movement (time of image change of mutual location of aiming equipment) (is set from 0,5 till $1 \mathrm{~s}$ (multiples of $0,1 \mathrm{~s}$ )); time taken for making decision concerning the direction of a hole deviation from the center of the target (can be defined 2 , 3, 4, 5 seconds); amount of shots (can be defined 10, 20, 30, 40, 50 shots).

Stages of teaching: the 1st stage - teaching front sight cover leveling - teaching shooting "mark" while shooting "while sheet"; the $2^{\text {nd }}$ stage - teaching shooting " mark" in 
case of "straight" front sight cover and "uneven" front sight; the $3^{\text {rd }}$ stage- teaching shooting "mark" in terms of "even" front sight and "uneven" front sight cover; the $4^{\text {th }}, 5^{\text {th }}$ and the $6^{\text {th }}$ stage - teaching shooting "mark" in terms of different ratio of "uneven" front sight and "uneven" front sight cover.

Estimating indices : «perfect»-90\% of correct answers ; «good»-80\% of correct answers ; « satiosfactory » $-70 \%$ of correct answers.

\subsection{Teaching defining the average impact point}

In order to teach a young biathlete correcting the sight during dry zeroing (preparing weapon for normal action) and shooting in windy weather (shooting with aiming point "removal"), it is necessary to teach defining the average impact point. During creating the methodology of teaching defining the average impact point with the help of electronic portable devices we took into consideration the experience of the programs use. It was created for a computer [12].

The choice of the target ("Biathlon” target or sports target №7).

The choice of number of holes on the target (from 3 to 10).

Placing holes (dots)on the target is realized « manually » in order to activate attention of young biathletes. By means of placing cursor into a necessary part of the target and setting the chosen point (point of bullet and target meeting) by means of the left mouseclick (on computer) or by means of touching the screen (a mobile phone or a pad). After the chosen dot stating on the target there appears the circumference inside of which there is the number of the shot.

The conditions of automatic holes (dots) input: holes (dots of meeting) should be placed inside the circumference with the diameter $40 \mathrm{~mm}$. The center of this circumference shouldn't be outside the " 7 " size of the $7^{\text {th }}$ sports target (not far than $29,2 \mathrm{~mm}$ from the center of the target).

Estimating indices: "perfect"- the average point of impact (API) is defined with the mistake till $5 \mathrm{~mm}$; "good" - API is defined with the mistake from 6 till $10 \mathrm{~mm}$; "satisfactory" - API is defined with the mistake from 11 till $15 \mathrm{~mm}$.

\subsection{Teaching correcting the sight}

After teaching a young biathlete defining the average point of impact it is necessary to teach him correct the sight during dry zeroing. For this purpose we created the following algorithm.

The choice of the target ("Biathlon” target or sports target №7).

Introducing the «worth» of one click of backsight drum. Sports small-bore rifles, which are used in biathlon (Biathlon, Anschutz), can have the sights with different "worth" of one click of backsight drum. The volume of bullet and target meeting point shift during one click of backsight drum can be $2,5 \mathrm{~mm}$ or $3 \mathrm{~mm}$ (Biathlon rifles); $5 \mathrm{~mm}$ (Anschutz rifles). Introduction of one click of backsight drum "worth" is realized by means of choosing necessary number from the list- $2,5 \mathrm{~mm}, 3 \mathrm{~mm}, 5 \mathrm{~mm}$.

The average impact point introduction. The average impact point introduction is realized by means of cursor placing to necessary part of the target and the chosen place stating pushing the left mouseclick (on computer) or by touching the screen (on pad or mobile phone). On the chosen place of the target there appears + . It means the average impact point.

The conditions of the average impact point introduction : it is necessary to locate the average impact point not far than size « 6 » of sports target № 7 (inside the circumference with diameter $74,4 \mathrm{~mm}$ ). 
The conditions of the program creation : for « teaching » regimen on the background of the target it is necessary to place the net (in a form of many dots) with the cell $2,5 \mathrm{~mm}, 3$ $\mathrm{mm}$ or $5 \mathrm{~mm}$ (depending on the set price of one click of a backsight drum) at the intersection of the lines with which the average impact point is set. For "control" regimen there is no any net, but the average impact point is placed at one of the intersection of the net lines.

Estimating indices: "perfect" - total mistake of corrections into the sight (in horizontal and vertical direction) isn't more than two clicks of a backsight drum; "good" - total mistake of corrections into the sight (in horizontal and vertical direction) isn't more than three clicks of a backsight drum; "satisfactory"- total mistake of corrections into the sight (in horizontal and vertical direction) isn't more than four clicks of a backsight drum.

\subsection{Teaching offset shooting}

In terms of wind three ways of shooting are used: waiting for the end of the wind blow; correcting the sight; offset shooting from the point of aiming.

The first way - shooting with waiting for the end of the wind blow can be used only in case of choppy wind.

The second way - shooting with corrections of the sight helps to preserve an athlete usual way of aiming and doesn't demand thinking over - «where and does the wind blow and what is its power? ». The decision concerning the corrections of the sight makes the coach and informs the aqthlete 30-40 seconds before biathlete's attmpt to overcome firing line. During this time period the wind situation can change. Moreover, during sight correction mistakes can be made (Biathlon and Anschutz rifles sight corrections are made by means of drum turning in opposing sides).

The third way - shooting with aiming point "removal" helps to avoid mistakes during sight corrections and is one of the most prospective way of shooting in terms of a wind. However, this way of shooting in terms of wind demands biathlete's skills to estimate wind situation and make decisions concerning the place of aiming point - direction and distance from the center of the target.

The work of A.I. Kudelin with the national biathlone teams of Russia provided his works concerning the topic of teaching biathletes shooting with aiming point "removal". The offered by the author methodology of teaching includes 9 stages $[13,14,15]$. The first five stages are trained at SCATT training simulator, the 6th and the 7th stages - in terms of realpaper target shooting, the 8th and the 9th stages- at control trainings and not high level competitions [16]. The author considers that the accuracy during shooting with aiming point "removal" can be provided while using circular front sight with the hole diameter from 3,0 till 3,5 $\mathrm{mm}$.

There are other research works, which are dedicated to the methodologies of teaching biathletes shooting substantiation in terms of wind $[17,18,19,20]$. As a rule these methodologies contain the complexes of shooting exercises. They are fulfilled at a shooting training simulator SCATT and shooting range.

We offer to use such methodology, which provides shooting visualization with aiming point "removal". The task visualization is realized by means of presenting a biathlete images of wind flags, with the help of which he should define the direction and power of side wind (head and tail wind are ignored). Teaching is realized in the following way: biathlete sees the image of wind flags and taking them into consideration he chooses the aiming point (by means of "full sight" removal into a chosen aiming point). "Full sight" removal into a chosen aiming point on the screen of a pad or a mobile phone is realized by means of pushing "left-right-up-down" pointers. Teaching includes two stages: the $1^{\text {st }}$ stage- "sighting in terms of side wind of different power"; the $2^{\text {nd }}$ stage - "sighting in terms 
of side wind of different power" $\rightarrow$ shooting in terms of power and direction of the wind change ».

\subsubsection{The first stage of teaching - "sighting in zero wind" shooting in terms of side wind of different power":}

The research results carried out by Yurev A.A. (1976) showed that bullet deviation from the center of the target under the influence of a side wind during shooting from small-bore rifle were the following: in terms of a weak wind $(2 \mathrm{~m} / \mathrm{sec})$ the bullet deviation is $1,5 \mathrm{~cm}$ (till size «9» of sports target № 7); in terms of a moderate wind $(4 \mathrm{~m} / \mathrm{sec})$ the bullet deviation is $3,0 \mathrm{~cm}$ (till size $《 7 \gg)$; in terms of a strong wind $(8 \mathrm{~m} / \mathrm{sec})$ the bullet deviation is $6,0 \mathrm{~cm}$ (till size «3») [21].

Zubrilov R.A. (2013) experimentally revealed the volumes of bullets deviations from the center of the target under the influence of side winds of different power in terms of using in modern biathlon sports rifles and chucks. In terms of a weak wind (till $2 \mathrm{~m} / \mathrm{sec}$ ) the bullet deviation from the center of a target is $13,2 \mathrm{~mm}$ (till size « $(9 »)$; modertae wind (till 4 $\mathrm{m} / \mathrm{sec}$ ) - deviation is $21,2 \mathrm{~mm}$ (till size $\langle 9 »)$; strong wind (till $8 \mathrm{~m} / \mathrm{sec}$ ) - deviation is 29,2 $\mathrm{mm}$ (till size «7») [22,23]. Under the influence of a side wind bullets deviation happens from the center of the target in the direction of «10 hours » (in case of left wind) and from the center in the direction of « 4 hours » (in case of right wind).

In terms of a weak wind shooting with aiming point "removal" is senseless.

Tail and head wind remove the bullet insignificantly and aiming point "removal" in these cases can be avioded. That is why in order to teach biathletes shooting with aiming point "removal" it is sufficient to use two wind directions : from the left and the right and two volumes of wind power - moderate and strong.

The order of working with the program is the following : during 5 seconds the athlete is shown the image (photo or video) of a wind flag, on which the wind of different power and direction influences. The amount of the demonstrated images of a flag is five. Two images of the flag for a moderate wind; ywo for a strong wind and one image for zero wind. The images of the flag are presented in perspective - from the altitude of the average height biathlete, close to firing line (10-5 meters) - on the left-behind wind flags. They are placed 5 meters from the firing line. During 3-5 seconds a biathlete estimates the direction and power of the wind and makes a decision about the place of the aiming point.

After the flag demonstration a biathlete sees the image of aiming equipment on the screen (in a form of a full sight in the center of the target), in the regimen of teachingvertical and horizontal lines. They cross in the center of the target (rectangular coordinate system) and also the pointers for full sight movement vertically and horizontally.

Vertical and horizontal lines are «connected» with the image of the aiming equipment. Biathlete moves the aiming equipment into a chosen aiming point with the help of the corresponding pointers. Vertical and horizontal lines (their crossing ) helps to visualize own actions and master the rules of shooting with aiming point "removal" quicker.

The measure of the aiming equipment removal is defined by the amount of pointer button pushing. However, a button pushing corresponds with the "worth » of one click of a backsight drum (2,5 mm, $3 \mathrm{~mm}$ or $5 \mathrm{~mm})$.

The order of work with the teaching program.

The size of the aiming equipment choice : the diameter of dioptrical sight hole choice ; the diameter of circular front sight hole (firm(small) - the average-free (big)); the kind of a circular front sight (the sight is attached on a front sight cover below or on the left or on the right).

The number of tasks choice (10, 20, 30). Time for making decisions choice (from 3 to 5 seconds). 
The level of accuracy choice : 1 level of difficulty - the chosen aiming point is defined with the mistake till $5 \mathrm{~mm}$; 2 level of difficulty — the chosen aiming point is defined with the mistake from 6 till $10 \mathrm{~mm}$; 3 level of difficulty — the chosen aiming point is defined with the mistake from 11 till $15 \mathrm{~mm}$.

Estimating indices : "perfect»- aiming point is defines correctly in $90 \%$ of cases; " good 》 - aiming point is defines correctly in $80 \%$ of cases; "satisfactory» — aiming point is defines correctly in $70 \%$ of cases.

\subsubsection{The second stage of teaching - "sighting in terms of side wind of different power" shooting in terms of wind power and direction change"}

The order of working with the teaching program :

1. An athlete is given the image of a wind flag, during sighting - side wind of strong or average power.

2. An athlete is given the image of the $2^{\text {nd }}$ flag, a wind flag during transfer to a firing line.

2.1. Power of wind change (without its deirection chnage - side wind of the smae direction, but different power (including zero wind).

2.2. Wind direction and power chnage - side wind of the opposite direction and different power.

3. After the decision making an athlete defines the place of the aiming point.

\section{Conclusions}

The availability of electronic portable devices of biathletes and pre-induction youth to teaching programs should be realized through login and password from the sites of additional education establishments. They would help to get reflexion, estimate the effectiveness of the teaching programs, develop the programs and specify the estimating indices.

The size of the used electronic device screen should be no less than $150 \times 150 \mathrm{~mm}$ (in this case $110 \times 110 \mathrm{~mm}$ target can be placed on the screen $1: 1$ ). It would help to decrease image distortion.

\section{References}

1. N.V. Astafev, N.G. Bezmelnitsyn, Urgent questions of skiing: Collection of scientific articles (Omsk, 4-9, 1994)

2. V. Vorona, A. Ratov, Physical education, sport and health culture in modern society, 3, 201-203 (2008)

3. N.V. Astafev, N.G. Bezmelnitsyn, Analyzing qualitative characteristics of shooting in biathlon (Omsk, 1990)

4. N.V. Astafev, Scientific works. 2006 Almanakh, 85-89 (2007)

5. Ya.S. Romanova, N.S. Zagurskiy, Materials of the VI All-Russian scientific-prictical conference «Modern system of sports training in biathlon» (132-143, 2018)

6. K.V. Ponomareva, Economical research works and works, 1, 17-24 (2018)

7. S.N. Zvereva, Theory and Practice of Physical Culture, 3, 79-80 (2015)

8. N.V. Astafev, Shooting technique improvement among biathletes on the basis of urgent information use concerning the process of aiming, achieved by means of SCATT training simulators ( LLC "Traiding house "Soviet sport", Moscow, 2020)

9. N.V. Astafev, Urgent problems of physical and special training of force structures, 3, 136-145 (2016) 
10. N.V. Astafev, A.P. Kosorotov, Electronic manual in complex with computer teaching program (Omsk, 2009)

11. N.V. Astafev, Materials of the I All-Russian scientific-practical conference «Modern system of spports traioning in biathlon» (Omsk, 28-32, 2011)

12. N.V. Astafev, A.P. Kosorotov, Electronic manual in complex with three computer teaching programs (Moscow, 2005)

13. A.I. Kudelin, N.S. Zagurskiy, Materials of the IV All-Russian scientific-practical conference «Modern system of spports traioning in biathlon» $(108-125,2015)$

14. A.I. Kudelin, N.S. Zagurskiy, Materials of the V All-Russian scientific-practical conference «Modern system of spports traioning in biathlon». (124-142, 2016)

15. A A.I. Kudelin, N.S. Zagurskiy, F. Khaytovich, Materials of the VI All-Russian scientificpractical conference "Modern system of spports traioning in biathlon» $(87-104,2018)$

16. E.S. Palekhova, A.I. Kudelin, I.I. Kochetov, A.A. Sukhanov, Patent of invention RU 2514966 C1, 10.05.2014. Application № 2012150101/11 23.11.2012.

17. P.A. Ropsovtsev, A.I. Kudelin, N.S. Zagurskiy, Ya.S. Romanova, Materials of the II All-Russian scientific-practical conference «Modern system of spports traioning in biathlon» (164-173, 2012)

18. N.V. Astafev, R.A. Zubrilov, Pedagogico-psychological and medico-biological problems of physical culture and sport, 10(3), 7-16, (2015)

19. N.V. Astafev, R.A. Zubrilov, Slobozhansky scientific and sports Bulletin, 2(52), 43-47 (2016)

20. Ya.S. Romanova, Scientific notes of P.F. Lesgaft University, 8(126), 123-129 (2015)

21. A.A. Yurev, Bullet sports shooting (Voenizdat, Moscow, 1976)

22. R.A. Zubrilov, Technique of shooting formation, development and improvement in biathlon (Soviet sport, Moscow, 2013)

23. A.S. Kuznetsov, Z.M. Kuznetsova, Russian Journal of Physical Education and Sport, 14(4), 5-7, (2019) 